\title{
Diversity and Abundance of Chrysopids in Different Ecosystems
}

\author{
Sravanthi Guntupalli*, M. Kalyanasundaram and R. Rajya lakshmi \\ Mango Research Station, Dr. Y. S. R. Horticultural University \\ Nuzvid - 521201, Krishna District, (A.P.), India \\ *Corresponding author
}

\begin{tabular}{l} 
Ke y w o r d s \\
$\begin{array}{l}\text { Mallada boninensis, } \\
\text { Chrysoperla, } \\
\text { Ecosystems, Rose, } \\
\text { Tapioca, Papaya, } \\
\text { Guava, Mango and } \\
\text { Sapota }\end{array}$ \\
\hline $\begin{array}{l}\text { Article Info } \\
\text { Accepted: } \\
\text { 06 June } 2018 \\
\text { Available Online: } \\
\text { 10 July } 2018\end{array}$ \\
\hline
\end{tabular}

\section{A B S T R A C T}

The present study was restricted to collection of insects belonging to the order Neuroptera and totally 5632 arthropods were collected. In total two families of Neuroptera were collected. More number of individuals fell under the family Chrysopidae (2995) followed by Hemerobidae (907). Four different sp. of chrysopids viz., C. zastrowi silemmi, M. boninensis, M. astur and Hemerobius sp. were recorded from all the six eco systems. More numbers of chrysopids viz., C. zastrowi silemmi, M. boninensis, M. astur and Hemerobius sp. were recorded in November and December (2013), whereas less numbers were recorded in May and in June (2013) months in rose ecosystem. More numbers of chrysopids were recorded in November and December (2013) followed by November (2012), whereas less numbers were recorded in May, June and in July (2013) months respectively in tapioca ecosystem. More number of chrysopids were recorded from October to December (2013) followed by November and in December (2012) whereas less numbers were recorded in June (2013) in papaya ecosystem. Chrysopids were relatively more in October and in November (2013) followed by November and December (2012) and relatively less numbers were recorded in May and June months (2013) respectively in mango ecosystem. More number of chrysopids were recorded from October to December (2012) followed by September to December (2013) whereas less numbers were recorded in May and June months (2013) in sapota ecosystem. Chrysopids were relatively more in October to December (2013) and in November to December (2012) and relatively less numbers were recorded in May and June months (2013) respectively in guava ecosystem.

\section{Introduction}

Among complex network of bioagents, Chrysopids or green lacewings are known to be the most effective predators, they belongs to order 'Neuroptera'. This order consists of a group of insects with soft bodies, biting mouthparts and two pairs of very similar membranous wings, which are usually held roof-like along the abdomen at rest. Their agricultural importance lies in their carnivorous habits. Green lacewings are considered to be one of the most effective generalist predators used in biological control. The larvae feed on pest aphids, scales, caterpillars, spider mites etc. infesting a variety of plants (McEwen et al., 2001). Adults are generally not predatory and feed on 
nectar, pollen or honeydew, while a few of them are predatory (Coppel and Mertins, 1977). Studies have demonstrated lacewings as effective predators of aphids, leaf miners, mites, thrips, whiteflies, eggs of leafhoppers, small caterpillars, citrus psylla, citrus black fly, scales and mealybugs etc. In recent years use of green lacewing species have been recommended for the IPM programmes (Nehare et al., 2004). Keeping in view the importance and use of chrysopid predators in different ecosystems diversity and abundance of chrysopids were recorded in different ecosystems.

\section{Materials and Methods}

Intensive survey was undertaken during September 2012 to December 13 in major horticultural ecosystems of rose, tapioca, papaya, mango, sapota, and guava in Salem, Coimbatore, Tirupur and Erode districts of Tamil Nadu with special reference to Neuroptera to calculate alpha diversity indices.

\section{Alpha diversity indices}

Alpha diversity indices are measures of species diversity (or richness) of a local community or habitat.

\section{Species richness indices}

\section{Species number (Magurran, 1987)}

This presents the total number of species in each sample.

\section{Shannon's diversity index (Batten, 1976)}

This represents the Shannon - Weiner (also called as Weaver) diversity index and is defined as:

$$
\begin{aligned}
& \mathrm{s} \\
& \mathrm{H}^{\prime}=-\Sigma \mathrm{Pi} \ln \mathrm{Pi}
\end{aligned}
$$

$\mathrm{i}=1$

where,

$\mathrm{H}^{\prime}$ is the species diversity index

$\mathrm{s}$ is the number of species, and

$\mathrm{Pi}=$ the proportion of individuals of each species belonging to the $i^{\text {th }}$ species of the total number of individuals.

This index is calculated using the natural logarithm. The higher the number, the higher is the species diversity.

\section{a) Fishers alpha (Fishers et al., 1943)}

This presents the alpha log series parameter for each sample. This is a parametric index of diversity that assumes the abundance of species and follows the log series distribution.

Ax, $a x^{2} / 2, a x^{3} / 3 \ldots a x^{n} / n$

where, $A x=$ the number of species to have one individual

$\mathrm{ax}^{2} / 2, \mathrm{ax}^{3} / 3 \ldots a \mathrm{x}^{\mathrm{n}} / \mathrm{n}=$ those with 2 individuals and so on.

Each term gives the number of species predicted to have $1,2,3 \ldots \mathrm{n}$ individuals in the sample. This is a useful index, which has been widely used.

\section{Margalef's D (Clifford and Stephenson, 1975)}

Margalef's D has been a favourite index for many years. It is calculated using the following formula.

$\mathrm{D}_{\mathrm{Mg}}=(\mathrm{S}-1) / \ln \mathrm{N}$

where,

$\mathrm{S}=$ the number of species recorded

$\mathrm{N}=$ the total number of individuals summed over all in $\mathrm{S}$ species 


\section{Brillouin diversity index (Magurran, 1987)}

The Brillouin index $(\mathrm{H})$, is calculated using:

$\mathrm{H}=\ln \mathrm{N} ! \sum_{\mathrm{i}=1}^{\mathrm{s}} \ln \mathrm{n}_{\mathrm{i}} ! / \mathrm{N}$

where,

$\mathrm{N}=$ the total number of individuals in the sample

$\mathrm{n}_{\mathrm{i}}=$ total number of individuals belonging to the $i^{\text {th }}$ species and the species number

\section{Species dominance indices}

\section{Simpson's diversity index (Simpson, 1949)}

Simpson's index (D) describes the probability that a second individual drawn from the population should be of the same species as the first. It is given by the following formula.

$\mathrm{D}=\Sigma \mathrm{n}(\mathrm{n}-1) / \mathrm{N}(\mathrm{N}-1)$

where,

$\mathrm{N}=$ the total number of organisms of all species and

$\mathrm{n}=$ the total number of organisms of a particular species

From which, Simpson's Diversity Index, 1 $\mathrm{D}$, is found. So, the larger its value, greater is the diversity.

Berger Parker diversity index (Berger and Parker, 1970; May, 1975)

Berger Parker index is a simple measure of species dominance. The index expresses the proportional importance of the most abundant species.

$\mathrm{d}=\mathrm{N}_{\max } / \mathrm{N}$

where,

$\mathrm{N}_{\max }$ is the number of individuals in the most abundant species and
$\mathrm{N}$ is the total number of individuals in the sample

This sample index was considered by May (1975) to be of the best indices. It is a simple measure of numerical importance of the most abundant species.

\section{McIntosh index (McIntosh, 1967)}

This index is calculated using the following formula proposed by McIntosh (1967).

$\mathrm{D}=\mathrm{N}-\mathrm{U} / \mathrm{N}-\sqrt{ }(\mathrm{N})$

$\mathrm{U}=\sqrt{ }\left(\Sigma \mathrm{n}_{\mathrm{i}}^{2}\right)$

where,

$\mathrm{N}$ is the total number of individuals in the sample and

$\mathrm{U}$ is given by the expression

$\mathrm{U}=\sqrt{ } \Sigma[\mathrm{n}(\mathrm{i})]$,

where,

$\mathrm{n}$ (i) is the number of individuals in the $i^{\text {th }}$ species and the summation is undertaken over all the species.

\section{Evenness indices}

Evenness (E) is a measure of the similarity between the abundance of different species, in a community. When evenness is close to the value one, it indicates that each species consists of the same number of individuals or that most of the individuals belong to one or a few species.

\section{Equitability J (Magurran, 1987)}

Equitability (J) or evenness refers to the pattern of distribution of the individuals between the species. This measure of equitability compares the observed ShannonWeiner index against that distribution of individuals between the observed species which would maximize diversity. If $\mathrm{H}$ is the observed Shannon-Weiner index, the 
maximum value this could take is $\log (\mathrm{S})$, where $S$ is the total number of the species in the habitat. It is indicated as follows.

\section{Record of predators}

During the survey other predators were also recorded in the field and identified by the scientist specialised in those fields or with the help of available reference collections.

\section{Results and Discussion}

The present investigation yielded 5632 individuals of arthropods belonging to the class insecta (most common) followed by Arachnida, Diplopoda and Chilopoda (Table 1). In current study, alpha diversity was estimated based on species number, ShannonWeiner index, Fisher alpha index, Margalef D index and Brillouin index, while dominance was based on Simpson, Berger-Parker and McIntosh indices. In these instances, the analyses were subjected to three levels of classification viz., based on family, genus and species. Species richness and diversity are commonly used for conservation purposes and to assess ecosystem fitness (Norton, 1986; Probst and Weinrich, 1993). However, Cardoso et al., (2004) confirmed the fact that inventories at species level require an enormous amount of resources mainly due to necessity of taxonomist employment. To reduce time and economic efforts, several opinions have been proposed by Duelli et al., (1999) such as reducing the analysis to particular species groups (e.g. Carabidae beetles) and/or to a subset sampled in the most diverse annual season. Other alternative methods not requiring species identification have been suggested; such as the use of morphospecies (Oliver and Beattie, 1993 and 1996) and higher taxa categories (Gaston and Williams, 1993) as surrogates for species. Bambach and Sepkoski (1992), Williams and Gaston (1994), Balmford et al., (1996) gave the opinion that the effectiveness of the higher taxa approach depends on a strong correlation existing between higher taxa richness and species richness. Andersen (1995) remarked that the use of this approach provides obvious benefits in a context of limited financial and human resources and it is particularly useful, when rapid biodiversity surveys are required.

In the present investigation, diversity indices were worked out at the familial, genus and species level to find out whether surrogacy is possible as far as neuropteran diversity analysis are concerned. Shannon Weiner Index at familial level and genus level showed strong correlation in papaya, tapioca and sapota ecosystems, whereas genus and species level analysis revealed strong correlation in sapota, mango and papaya ecosystems. At familial level and species level strong correlation was observed in papaya followed by sapota and in tapioca ecosystems. With reference to Fisher's Alpha, analysis at familial and genus, genus and species level an identical pattern was recorded in rose, tapioca, papaya and guava. Moderate and weak relationships are observed in sapota and mango respectively. Analysis of species diversity using this index gave a clear picture of the within habit species diversity. At familial level and species level significant correlation was observed in rose, tapioca and in guava ecosystems. Margalef D index also presented similar results to Fischer index from correlation analysis. Calculation based on Brillouin's index revealed neuropteran diversity at familial level and genus level showed strong correlation in tapioca and papaya and moderate correlation in mango and rose ecosystems, whereas genus and species level analysis revealed significant correlation in papaya, mango and guava. At familial level and species level strong correlation was recorded in papaya followed by mango ecosystems.

Simpson's dominance index at familial level and genus level showed strong correlation in 
papaya and moderate in tapioca and sapota ecosystems, whereas genus and species level analysis revealed strong correlation in rose and sapota ecosystems. At familial level and species level strong correlation was recorded in papaya ecosystem. Berger parker index at familial level and genus level showed strong correlation in mango and sapota. Genus and species level analysis also showed the same results. At familial level and species level strong correlation was recorded in papaya and mango ecosystems. The Berger-Parker index equals the inverse of true diversity of order infinity. In McIntosh index identical pattern was observed in papaya, sapota and tapioca at familial level and genus level but at species and genus level similarity was observed in sapota, mango and in guava. At familial level and species level strong correlation was observed in sapota followed by papaya and guava ecosystems. Equitability $\mathbf{J}$ indices were similar at terms of familial level and genus level in papaya and tapioca whereas at genus and species level pattern was identical in sapota followed by papaya and in mango ecosystems. At familial level and species level strong correlation was observed in papaya followed by sapota and tapioca ecosystems. The usage of higher taxa typically, family as surrogate for species has been suggested by Gaston and Williams (1993) and William and Gaston (1994). Hoback et al., (1999) reported that ideally an estimate of diversity should examine organisms at species level, as any estimate of diversity at taxonomically higher level will be unable to explain the relationship between the species or population size or rate.

Different species of neuropterans viz., $M$. boninensis, C. zastrowi silemmi $M$. astur and Hemerobius sp. dominated in different time intervals in rose ecosystem. In tapioca ecosystem $M$. boninensis, $C$. zastrowi silemmi and $M$. astur were dominant whereas Hemerobius sp. were less dominant. $M$. boninensis and C. zastrowi silemmi dominated mainly in papaya ecosystem. In mango and sapota ecosystem Hemerobius sp. and $M$. boninensis were dominant. In guava ecosystem three sp. of neuropterans viz., $C$. zastrowi silemmi, $M$. boninensis and Hemerobius sp. were equally sharing the ecosystem which indicates that ecosystem plays a major role in the survival of different organisms.

\section{Rose ecosystem}

In rose ecosystem results revealed that Hemerobius sp. dominated in September, October and in November (2012) followed by C. zastrowi silemmi. M. boninensis dominated in December (2012), January and in February (2013) months followed by $C$. zastrowi silemmi in December (2012) and Hemerobius sp. in February and March (2013) respectively. Hemerobius sp. dominated in April (2013) and in June (2013) but $M$. boninensis dominated in May (2013). $M$. boninensis dominated in July (2013) whereas Hemerobius sp. dominated in August and September (2013). In October and in November (2013) M. boninensis dominated followed by Hemerobius sp. whereas in December (2013) Hemerobius sp. dominated followed by $M$. boninensis.

\section{Tapioca ecosystem}

In tapioca ecosystem analysis of results revealed that $M$. boninensis dominated in September, October and in November (2012) months followed by $C$. zastrowi silemmi and $M$. astur whereas in December (2012) $C$. zastrowi silemmi dominated M. boninensis. In January (2013) C. zastrowi silemmi dominated followed by $M$. boninensis but in Febraury (2013) M. boninensis dominated followed by C. zastrowi silemmi in the tapioca ecosystem. From March to December (2013) $M$. boninensis dominated completely. Hemerobius sp. were less abundant when, 
compared to other sp. in the tapioca ecosystem.

\section{Papaya ecosystem}

From October (2012) to May (2013) $C$. zastrowi silemmi dominated followed by $M$. boninensis in papaya ecosystem. In June (2013) M. boninensis dominated followed by C. zastrowi silemmi. In July, August and in September (2013) C. zastrowi silemmi dominated followed by $M$. boninensis. In November and in December (2013) also $C$. zastrowi silemmi dominated followed by $M$. boninensis. M. astur and Hemerobius sp. were less abundant when compared to $C$. zastrowi silemmi and $M$. boninensis in papaya ecosystem.

\section{Mango ecosystem}

Hemerobius sp. dominated in mango ecosystem from September (2012) to March (2013) followed by $M$. boninensis whereas $M$. boninensis dominated from April (2013) to June (2013) followed by Hemerobius sp. Hemerobius sp. dominated in July (2013) whereas from August to October $M$. boninensis dominated followed by Hemerobius sp. in mango ecosystem. In November (2013) Hemerobius sp. dominated followed by $M$. boninensis and in December (2013) M. boninensis dominated followed by Hemerobius sp. C. zastrowi silemmi and $M$. astur were comparatively less in mango system.

Table.1 Arthropods at ordinal level in horticultural ecosystems

\begin{tabular}{|c|c|c|c|}
\hline Class & Order & Total & Grand total \\
\hline \multirow[t]{2}{*}{ Arachnidae } & Araneae & 84 & \multirow[t]{2}{*}{101} \\
\hline & Acarinae & 17 & \\
\hline Chilopoda & Scolopendridae & 5 & 5 \\
\hline Diplopoda & Pentazonia & 9 & 9 \\
\hline \multirow[t]{12}{*}{ Insecta } & Odonata & 84 & \multirow[t]{12}{*}{5517} \\
\hline & Orthoptera & 112 & \\
\hline & Dictyoptera & 94 & \\
\hline & Dermaptera & 23 & \\
\hline & Hemiptera & 386 & \\
\hline & Isoptera & 14 & \\
\hline & Thysanoptera & 13 & \\
\hline & Hymenoptera & 248 & \\
\hline & Coleoptera & 373 & \\
\hline & Diptera & 122 & \\
\hline & Lepidoptera & 146 & \\
\hline & Neuroptera & 3902 & \\
\hline Grand total & & & 5632 \\
\hline
\end{tabular}


Fig.1 Seasonal abundance of different species of neuropterans in different ecosystems

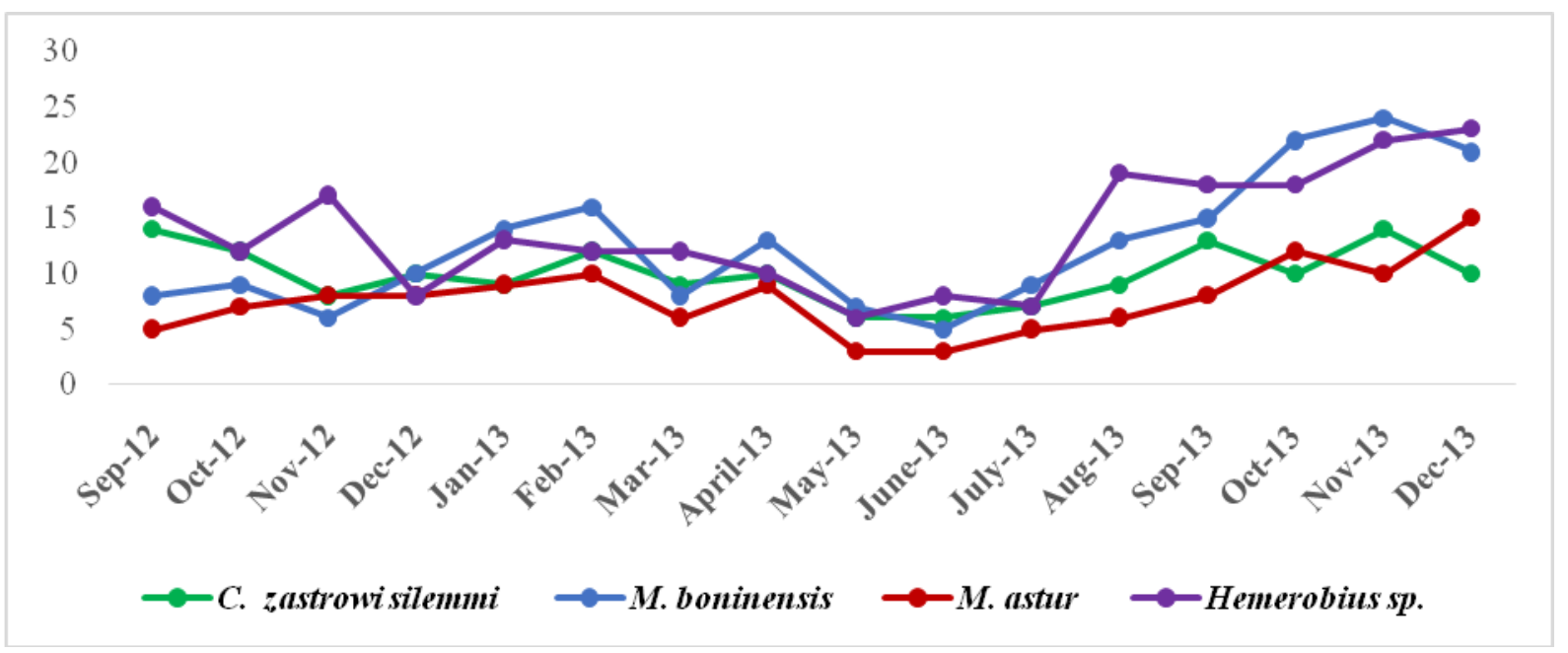

\section{(Rose ecosystem)}

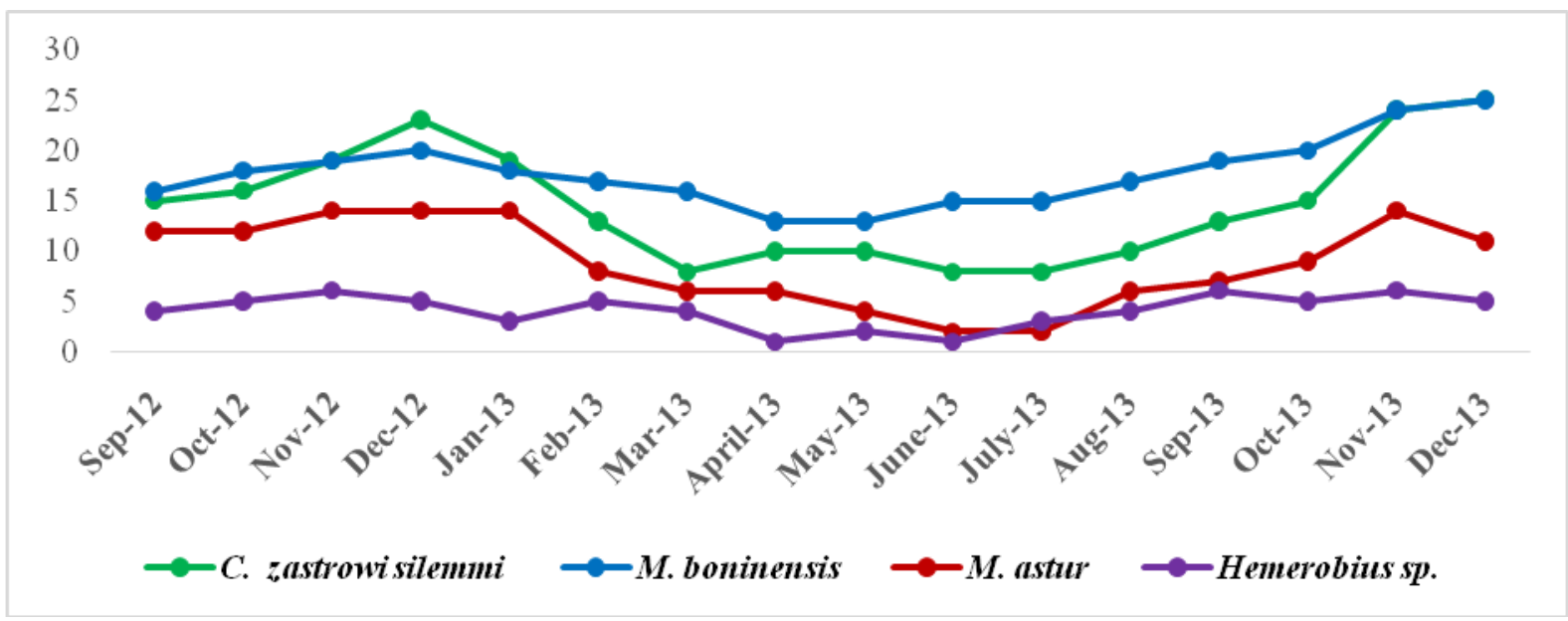

(Tapioca ecosystem)

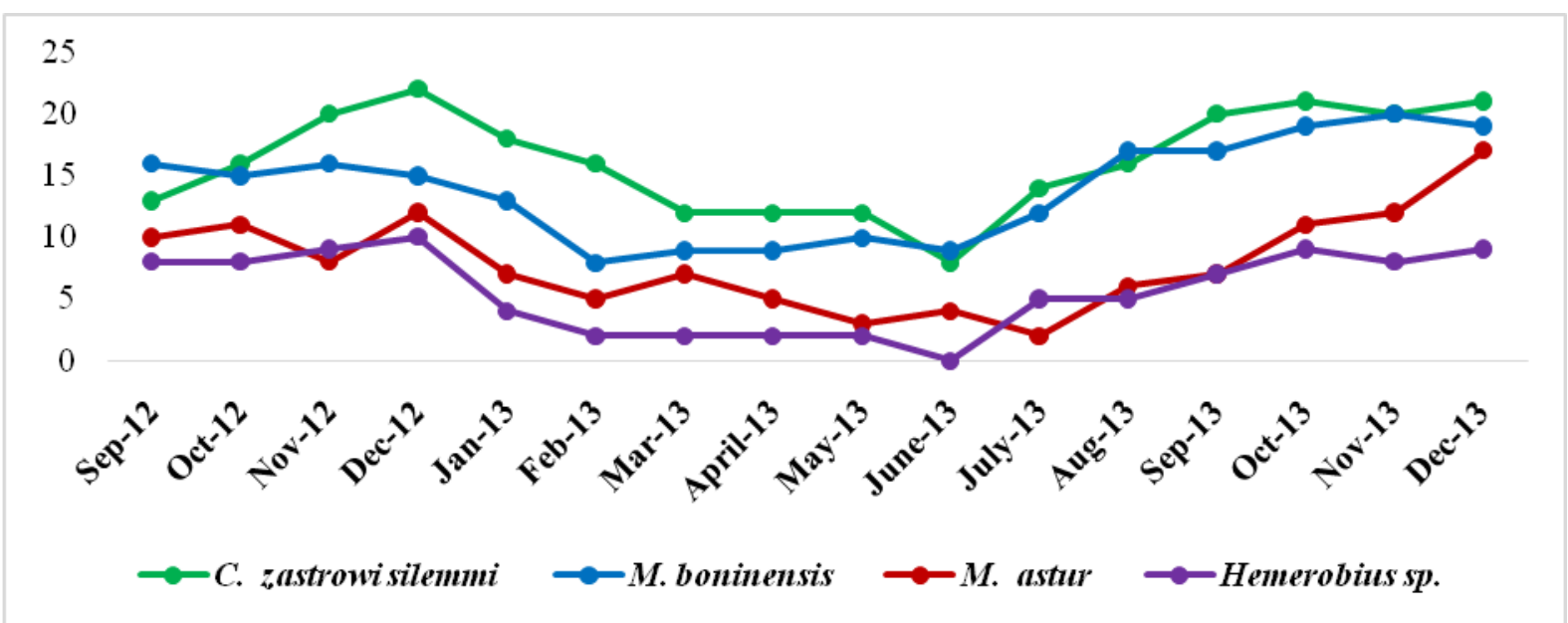

(Papaya ecosystem) 


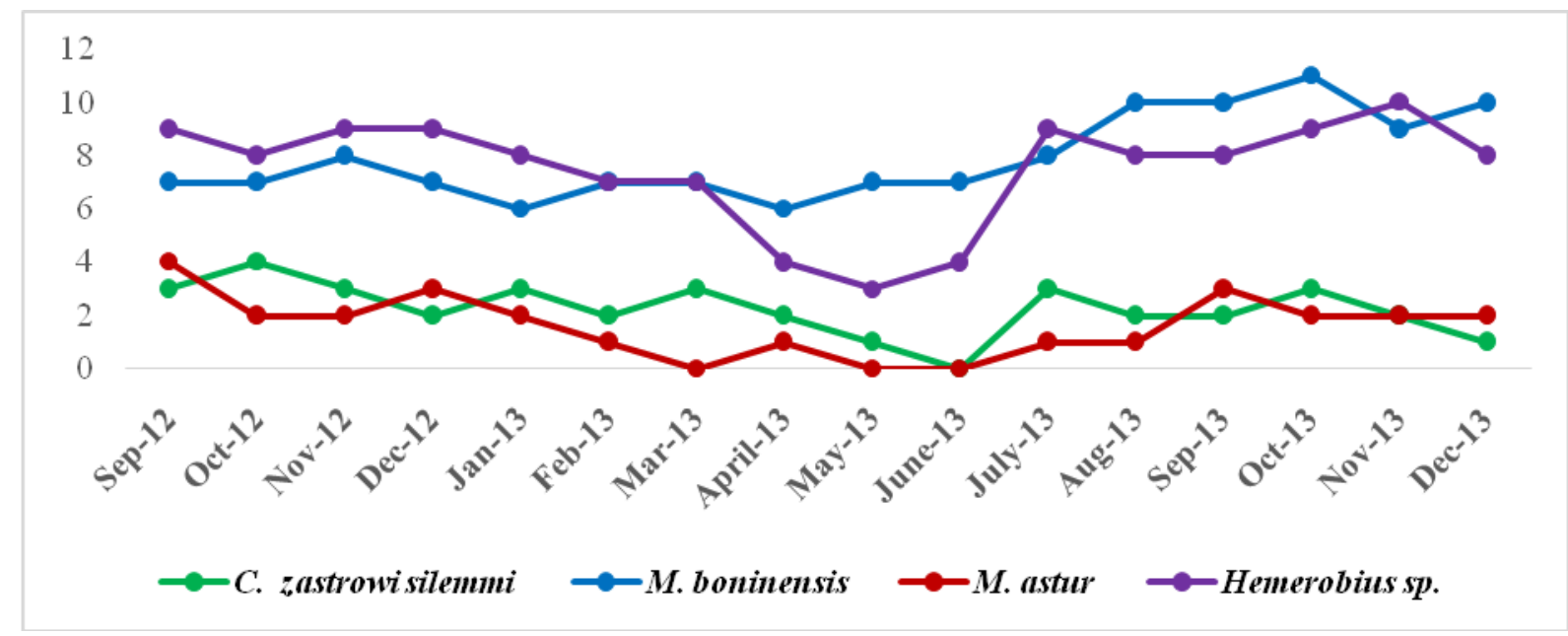

\section{(Mango ecosystem)}

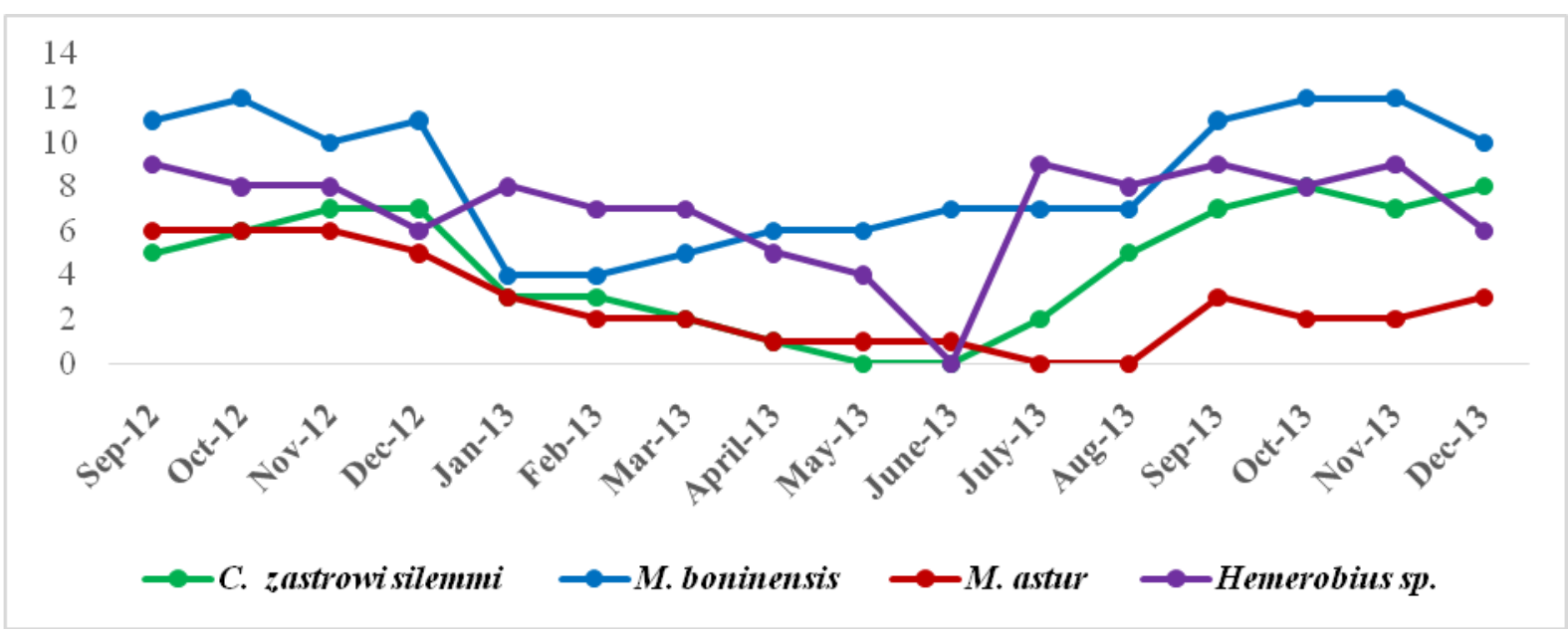

(Sapota ecosystem)

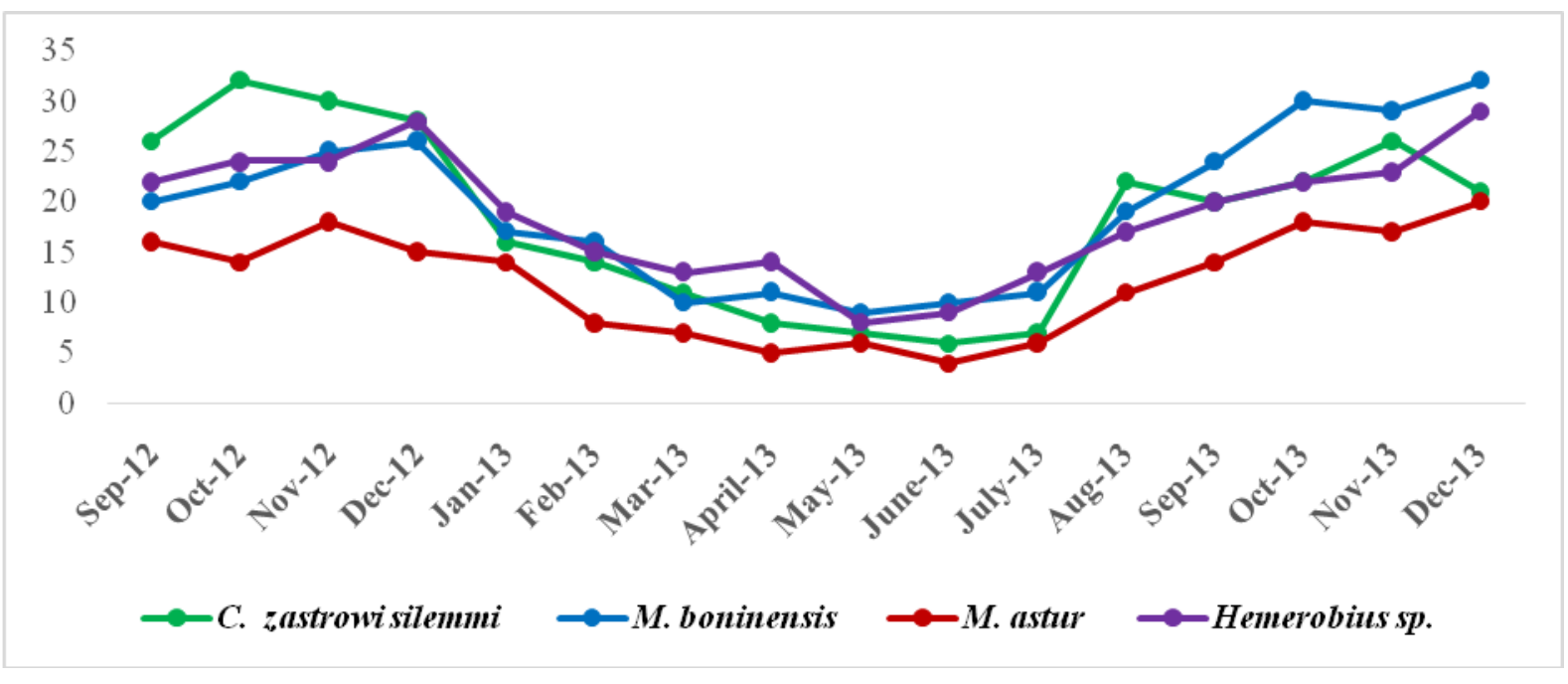

(Guava ecosystem) 


\section{Sapota ecosystem}

In sapota ecosystem $M$. boninensis dominated from September (2012) to December (2012) followed by Hemerobius sp whereas Hemerobius sp. dominated from January (2013) to April (2013) followed by M. boninensis. C. zastrowi silemmi were not recorded in May and June (2013) months whereas M. astur were not recorded in July and August (2013) months. Hemerobius sp.dominated in July and in August (2013) followed by M. boninensis. From September to December $M$. boninensis dominated followed by Hemerobius sp and $C$. zastrowi silemmi.

\section{Guava ecosystem}

Three sp. of neuropterans viz., C. zastrowi silemmi, M. boninensis and Hemerobius sp. were equally dominant from September (2012) to December (2013) in guava ecosystem whereas $M$. astur was less dominant compared to the other three sp. of neuropterans in guava ecosystem.

\section{Seasonal abundance of neuropterans in different ecosystems}

Four different sp. of chrysopids viz., C. zastrowi silemmi, $M$. boninensis, $M$. astur and Hemerobius $s p$. were recorded in all the six ecosystems.

The population of chrysopids was found maximum during the first fortnight of November and December when the temperatures were low and relative humidity was high at the same time the natural population of insects viz., mango hoppers, mealy bugs, scales and thrips were higher on mango trees. The activity of predator remained low during high temperature in the month of April to August (More et al., 2011). In the present study almost in all the ecosystems surveyed viz., rose, tapioca, papaya, mango, sapota and guava, neuropterans were abundantly present during November and December months and low in number during April, May and June months.

\section{Rose ecosystem}

More number of four sp. of chrysopids viz., $C$. zastrowi silemmi, M. boninensis, $M$. astur and Hemerobius $s p$. were recorded in November (2013) followed by December (2013) and in October (2013) whereas less numbers were recorded in May and in June (2013) months in rose ecosystem (Fig. 1).

\section{Tapioca ecosystem}

Four different sp. of chrysopids viz., C. zastrowi silemmi, $M$. boninensis, $M$. astur and Hemerobius sp. were recorded in tapioca ecosystem. More numbers of chrysopids were recorded in November (2013), December (2013) followed by November (2012) whereas less numbers were recorded in May, June and in July (2013) months respectively (Fig. 1).

\section{Papaya ecosystem}

More number of chrysopids were recorded from October to December (2013) followed by November and in December (2012) whereas less numbers were recorded in June (2013) (Fig. $1)$.

\section{Mango ecosystem}

Chrysopids were relatively more in October and in November (2013) followed by November and December (2012) and relatively less numbers were recorded in May and June months (2013) respectively (Fig. 1).

\section{Sapota ecosystem}

More number of chrysopids were recorded from October to December (2012) followed by September to December (2013) whereas less numbers were recorded in May and June months (2013) (Fig. 1).

\section{Guava ecosystem}

Chrysopids were relatively more in October to December (2013) and in November to 
December (2012) and relatively less numbers were recorded in May and June months (2013) respectively (Fig. 1).

\section{Acknowledgement}

Authors are grateful to the Department of science and Technology for providing fellowship to the senior author and also to the department of Entomology, TNAU for constant guidance and encouragement to carry out the research.

\section{References}

Anderson, A.N. 1995. Measuring more of biodiversity: genus richness as a surrogate for species richness in Australian ant faunas. Biological conservative, 73: 3943.

Balmford, A., M.J.B. Green and M.G. Murray. 1996. Using higher taxa richness as a surrogate for species richness. Proceedings of Regional Society of London, 263: 1267-1274.

Bambach, R.K. and J.J Sepkoski.1992. The fossil record and marine diversity at different taxonomic levels. Paleontology Society of Species Publication, 6: 16-36.

Cardoso, P., I. Silva, N. G. Oliveira de and A. R. M. Serrano. 2004. Higher taxa surrogates of spider diversity and their efficiency in conservation. Biological Conservation, 117: 453-459.

Coppel, H.C. and J.W. Mertins. 1977. Biological Insect Pest Suppression. Springer, Berlin.

Duelli, P., M.K. Obrist and D.R. Schmatz. 1999. Biodiversity evaluation in agricultural landscapes: above ground insects. Agricultural Ecosystems and Environment, 74: 33-64.

Gaston, K.J. and P.H. Williams. 1993. Mapping the world's species-the higher taxon approach. Biodiversity letter, 1:2-8.

Hoback, W., M. Tina, M. Swados, M. Stephenson, P. Sponer and G. Leon. 1999. Trap colour and placement affects estimates of insect family level abundance and diversity in a Nebraska salt marsh. Entomologica Experimentalis et Applicata, 91: 393-402.

McEwen, P. K., T. R. New and A. Whittington (Eds.). 2001. Lacewings in the Crop Environment. Cambridge University Press, Cambridge, UK, pp. 546.

More, S. A., P. D. Patil and B. D. Shinde. 2011. Safety of different insecticides to the green lace wing, Mallada boninensis Okomoto. Journal of Plant Protection and Environment, 8(1): 21-25.

Nehare, S.K., V.Y. Deotale., R.O. Deotale and P.N. Dawane. 2004. Biology and predatory potential of Mallada boninensis (Okamoto) against sucking pests. Journal of Soils and Crops, 14 (2): 427-432.

Norton, B.G. 1986. The preservation of Species. Princeton University Press, Princeton. pp.121-234.

Oliver, I. And A.J. Beattie. 1993. A possible method for the rapid assessment of biodiversity. Conservative Biology, 7:562-568.

Oliver, I. And A.J. Beattie. 1996. Invertebrate morphospecies as surrogates for species: a case study. Conservative Biology, 10:99109.

Probst, J. R and J. Weinrich. 1993. Relating Kirtland's wabler population to changing landscape composition and structure. Landscape ecology, 8: 257-273.

Williams, P.H. and K.J. Gaston. 1994. Measuring more of biodiversity: can higher-taxon richness predict wholesale species richness? Biological Conservative, 67: 211-217.

\section{How to cite this article:}

Sravanthi Guntupalli, M. Kalyanasundaram and Rajya Lakshmi, R. 2018. Diversity and Abundance of Chrysopids in Different Ecosystems. Int.J.Curr.Microbiol.App.Sci. 7(07): 790-799. doi: https://doi.org/10.20546/ijcmas.2018.707.096 